\title{
General and Specific Considerations as to why Osteoporosis-Related Care Is Often Suboptimal
}

\author{
Elizabeth M Curtis ${ }^{1} \cdot$ Stephen Woolford ${ }^{1} \cdot$ Claire Holmes $^{2} \cdot$ Cyrus Cooper $^{1,3,4} \cdot$ Nicholas C Harvey $^{1,4}$
}

Published online: 26 February 2020

(C) The Author(s) 2020

\begin{abstract}
Purpose of Review The assessment of fracture risk and use of antiosteoporosis medications have increased greatly over the last 20-30 years. However, despite this, osteoporosis care remains suboptimal worldwide. Even in patients who have sustained a fragility fracture, fewer than $20 \%$ actually receive appropriate antiosteoporosis therapy in the year following the fracture. There is also evidence that treatment rates have declined substantially in the last 5-10 years, in many countries. The goal of this article is to consider the causes for this decline and consider how this situation could be remedied.

Recent Findings A number of possible reasons, including the lack of prioritisation of osteoporosis therapy in ageing populations with multimorbidity, disproportionate concerns regarding the rare side effects of anti-resorptives and adverse changes in reimbursement in the USA, have been identified as contributing factors in poor osteoporosis care.

Summary Improved secondary prevention strategies; screening measures (primary prevention) and appropriate, cost-effective guideline and treatment threshold development could support the optimisation of osteoporosis care and prevention of future fractures.
\end{abstract}

Keywords Osteoporosis $\cdot$ Epidemiology $\cdot$ Fracture $\cdot$ Adverse effects $\cdot$ Treatment gap $\cdot$ Policy

\section{Introduction}

The management of osteoporosis-its diagnosis, the assessment of fracture risk, the development of therapies and best practice guidelines to reduce the risk of fractures - has advanced hugely over the past 30 years. However, many studies indicate that the care of people with osteoporosis is still not

This article is part of the Topical Collection on Quality of Care in Osteoporosis

Elizabeth M Curtis

bc@mrc.soton.ac.uk

1 MRC Lifecourse Epidemiology Unit, Southampton General Hospital, University of Southampton, Southampton, UK

2 Rheumatology Department, University Hospitals Southampton NHS Foundation Trust, Southampton, UK

3 NIHR Oxford Biomedical Research Unit, University of Oxford, Oxford, UK

4 NIHR Southampton Biomedical Research Centre, University Hospitals Southampton NHS Foundation Trust, University of Southampton, Southampton, UK optimal; indeed, most men and women at high fracture risk do not receive treatment [1]. This is true even in patients who have sustained a fragility fracture, with, in many cases, fewer than $20 \%$ actually receiving therapies to reduce the risk of fracture in the year following the fracture [2, 3]. Rates of treatment are particularly poor for older women and those living in long-term care. Large gaps in service provision exist, as indicated by the fact that the use of fracture risk assessment tools such as FRAX® varies one thousand-fold worldwide. This variability is far greater than the 30 -fold variation in crude, or 10-fold variation in age-standardised hip fracture incidence globally $[4,5]$. Global differences in availability of internet access, availability of national assessment guidelines for osteoporosis in many countries and the availability of alternative assessment algorithms only partially explain these differences [4].

Whilst the under-assessment and treatment of those at very high risk of further fracture is of great concern, even more alarming is the apparent downward trend in treatment with antiosteoporosis medications after hip fracture, which has been demonstrated both in the US, European and UK populations [6, 7]. There are many potential causes for this trend, including the elevation of concerns regarding rare 
antiresorptive drug-related side effects such as atypical femoral fractures and osteonecrosis of the jaw and the recent changes to treatment reimbursement in the USA. In this review, we give an overview of the reasons for suboptimal osteoporosis care, or "treatment gaps", at all levels, and discuss possible approaches to remedy this problem.

\section{What Do We Mean by "Suboptimal" Osteoporosis Care?}

It is widely recognised that disparities exist between the population at high fracture risk, or who have experienced a low trauma fracture, and the number who receive appropriate osteoporosis assessment and treatment [1]. As an example, in the UK, analysis of the Clinical Practice Research Datalink (CPRD) has demonstrated inadequacies in both primary and secondary fracture prevention. Initial improvements in prescription rates were encouraging; following a hip fracture in the UK, the probability of antiosteoporosis drug prescription increased from just $7 \%$ in 2000 to $46 \%$ in 2010 [8], with older patients ( $\geq 75$ years of age) particularly benefiting from this trend. At any given point in time, the cumulative incidence of antiosteoporosis therapy was greater in women (8\% in 2000 , $51 \%$ in 2010) than in men (4\% in $2000,34 \%$ in 2010). Given this steady increase in the awareness of the need for antiosteoporosis drugs over a 10 -year period, a continued trend in increased prescribing would have made perfect sense. However, despite fewer than $50 \%$ of hip fracture patients receiving treatment, from around 2011, a plateau and a possible decrease in prescriptions has occurred in the UK [9•]. Local trends in prescribing antiosteoporosis therapies appeared to persist over time, with substantial geographic heterogeneity within the UK, for example, in the North East of the UK the odds ratio for antiosteoporosis medication following a hip fracture was $1.29(95 \%$ CI $0.89,1.87)$ and in the South Central region $0.56(95 \%$ CI $0.43,0.73)$, the North West being the referent. Over the subsequent 5 years of follow-up, these geographic trends persisted indicating systematic differences in provision of osteoporosis care [10].

Such patterns in secondary fracture prevention are present in many countries. A prospective observational study of over 60,000 older women recruited from primary care practices in 10 countries across USA, Europe and Australia (the GLOW study) demonstrated that over $80 \%$ of women with a fragility fracture did not receive osteoporosis treatment [11]. In another international prospective study of 1795 patients who sustained a low trauma hip fractures in ten countries (Australia, Austria, Estonia, France, Italy, Lithuania, Mexico, Russia, Spain, and the UK), just $27 \%$ were prescribed antiosteoporosis therapy after the hip fracture [12].

Trends in prescribing (incorporating both primary and secondary prevention) are consistent with these findings. Figure 1 shows that antiosteoporosis medication prescription rates in the UK rose from 2.3 to 169.7 prescriptions per 10,000 person-years amongst women from 1990 to 2006. However, following this rise, prescription rates plateaued and then decreased by $12 \%$ between 2009 and 2012 (Fig. 1). In men, prescription rates rose less steeply from 1990 to 2007 and then plateaued from 2008 onwards, with marked differences in prescription of antiosteoporosis medications according to ethnicity and geographic location in both sexes [13].

Treatment uptake for osteoporosis similarly increased in Europe up to 2008, thereafter plateaued, and in more recent years has fallen (Fig. 2). Within Europe, there is marked intercountry variation in the treatment penetration of individuals at high risk of osteoporotic fracture - in a recent study the percentage of patients at high fracture risk (defined using FRAX ${ }^{\circledR}$ ) who were not treated (also known as the treatment gap) varied from just $25 \%$ in Spain to $95 \%$ in Bulgaria. It was estimated that, within the EU in 2010, out of the 21.3 million men and women who exceeded FRAX high risk level, 12.3 million were untreated [12, 14-17]. These estimates are conservative (since treatment will have been given to an unknown proportion of low risk women) [18], though have been supported by findings from Spanish studies using individual-level data from primary care prescription databases from over 1.5 million participants [19]. In Danish registry studies, osteoporosis medication use plateaued in 2014 and declined thereafter. Interestingly, hip fracture rates also declined between 2005 and 2015 by $30 \%$, but only $20 \%$ (at most) of the observed reduction could be attributed to treatment. The authors concluded that the anti-osteoporosis therapy use was at too low a level to make a meaningful impact on the fracture burden within Danish society and represented a missed opportunity for reducing hip fracture rates [20].

Similar findings have emerged from a large retrospective analysis using US administrative insurance claims data of almost 100,000 men and women aged over 50 years who were

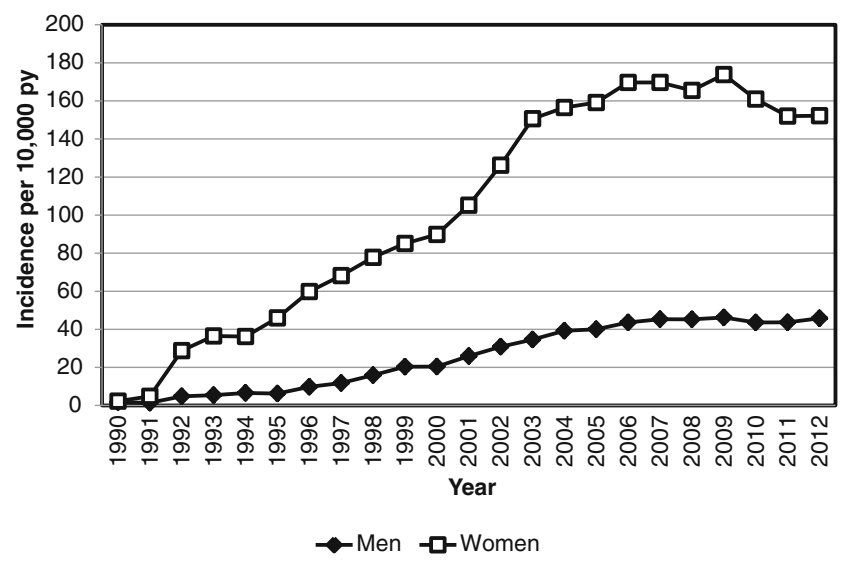

Fig. 1 Antiosteoporosis medication prescription incidence from 1990 to 2012 in the UK population aged 50 years or over, reproduced with permission from van der Velde et al. [13] 


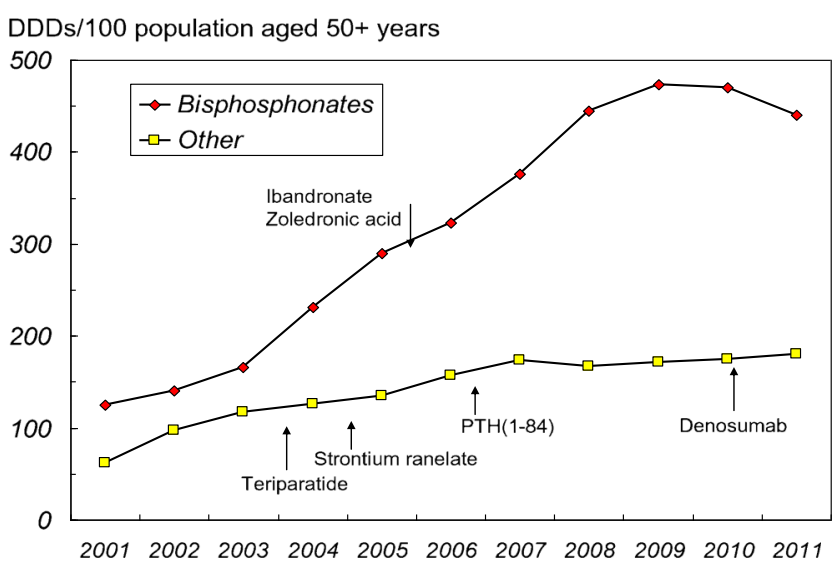

Fig. 2 Estimated sales of antiosteoporosis drugs (Defined Daily Doses, DDD)/100 population aged 50 + years from 2001 to 2011 in the European Union, reproduced with permission from Hernlund et al. [14]

hospitalised for hip fracture [6]. The study examined the uptake of osteoporosis medication within a year of hospital discharge; the estimated probability of receiving osteoporosis medication within this time period was $28.5 \%$ but showed a significant decline over a 10 -year interval, from $40.2 \%$ in 2002 to $20.5 \%$ in 2011 [6]. Findings from the US Medical Expenditure Panel Survey are supportive of this, demonstrating a marked reduction in the prevalence of bisphosphonate use from 2007 onwards, particularly amongst women [21].

\section{Why Is there a "Treatment Gap"-From Best Practice to Current Practice?}

\section{Awareness and Perception by Patients and Physicians}

As shown by the studies cited above, antiresorptive treatment rates both in primary and secondary fracture prevention increased until 5 to 10 years ago. The clinical situation was bolstered by policy and risk assessment advances, including the use of FRAX® and other risk calculators [22, 23] and guidance on intervention [15], combined with the availability of cheaper, generic bisphosphonates. In spite of this, outwardly prospering field treatment rates have declined in recent years, both in those at high risk of fracture and in those who have suffered a fracture, despite the huge expansion of the atrisk population [24].

Many factors appear to contribute to this phenomenon. One such reason is that strategies at a national and international level have not been implemented sufficiently to impact primary and secondary preventions. For patients and clinicians alike, the idea of managing a future "risk" makes primary fracture prevention more difficult, rather than treating a disease event which has already impacted upon the patient. Musculoskeletal diseases in general are viewed by policymakers and patients alike as a of lesser importance than outcomes such as cancers and heart disease [1], despite the fact that the musculoskeletal disease has been shown to be a leading course of disability worldwide by the Global Burden of Disease initiative [25].

In the case of osteoporosis, there is a stark mismatch between the perceived and actual severity of the condition. Many do not recognise that, for example, a hip fracture is associated with a $20 \%$ associated reduced survival compared with non-fracture peers and as such is a devastating life event [26]. Contrast this with a parallel event such as an acute myocardial infarction; it would be impossible to imagine that it would be acceptable in the developed world for less than $50 \%$ of such cardiac patients to receive risk-reducing therapies such as aspirin and other antiplatelet agents, antihypertensives and statins [27]. The large international women's cohort, GLOW, clearly documents this risk misperception, in which many underestimated their own fracture risk in comparison with their peers [28]. Perhaps, in a world where many populations are ageing and physicians and patients are dealing with multimorbidity, osteoporosis treatment falls to the bottom of the priority list.

Physicians' perceptions of osteoporosis and efficacy of treatments have been further confused by harmful and inaccurate conclusions about the treatment of osteoporosis in high impact journals including the British Medical Journal and Journal of Internal Medicine [29, 30]. These articles, claiming, for example that "the dominant approach to hip fracture prevention is neither viable as a public health strategy nor cost effective" and that "the main ways to prevent these fractures have not changed in nearly 25 years: stop smoking, be active and eat well" are frankly incorrect, unbalanced and refuted by overwhelming evidence (as stated by international and national societies such as the International Osteoporosis Foundation and the American Society for Bone and Mineral Research); nonetheless, such "fake news" presented in high impact journals has traction, and clear damage has been done [31].

\section{Concerns Regarding Medication Adverse Effects}

There are abundant data showing that alarming reports about osteoporosis medication in the media have been followed by a reduction in use of these medications, despite evidence that the benefits of treatment clearly outweigh the risks for the vast majority of users [32]. In order to better understand patients' concerns regarding medication safety, Jha et al. used data from the Medical Expenditure Panel Survey and National Inpatient Sample in the USA to examine relationships between medication use, internet searches for alendronate between 2006 and 2010, and safety concerns reported in the media [21]. Clear spikes of internet search activity were observed to correspond to events such as a 2006 lawsuit filed against Merck (for Fosamax allegedly causing osteonecrosis of the jaw (ONJ)), an ABC World News feature in 2010 on the associations 
between Fosamax and atypical femoral fractures (AFFs), and various other reports in the media of serious but rare side effects, set in parallel with the regression in bisphosphonate use by more than $50 \%$ between 2008 and 2012. The Australian Longitudinal Study on Women's Health findings was in keeping with the findings from the USA; antiosteoporosis medication use grew over the period 2000 to 2007 but then shrank from 2007 to 2010. In Australia, interventions to remedy this, including the relaxation of the indications for bone density testing and a subsidy for antiosteoporosis medications, had little effect, the most marked declines in prescriptions coincided with negative press for antiresorptive therapy such as a 2007 major report on ONJ [33].

In absolute terms, the serious long-term adverse side effects of bisphosphonates are very rare (with incidences in ranging from $1 / 100,000$ to $1 / 10,000$ per year) [34]. However, the approach to risk/benefit communication has largely been on the side of declaring risk, amongst the media (as demonstrated above), physicians and policymakers. The substantial impact of the underlying condition on morbidity and increased mortality, with fracture risk markedly decreased by antiosteoporosis medications, appears often forgotten in these discussions. For example, UK National Institute for Health and Care Excellence (NICE) recently issued guidance on multi-morbidity [35] and targeted bisphosphonates for review after 3-year treatment despite the evidence for their longerterm efficacy and safety being of greater reliability than the other treatments considered for 3-year review.

In a recent review of the benefits versus risks for BP therapy [36], the benefits for fracture reduction for short-term therapy for 3 to 5 years was shown to far outweigh any risks of AFFs. Using the set of assumptions about AFF risk with best evidence (relative risk of 1.7 for any BP use [37]), the study states that treating 10,000 osteoporotic women for 3 years would lead to the prevention of 1000 fractures (including 110 hip fractures) whilst causing only 0.08 AFFs. Put another way, for one AFF associated with 3 years of BP treatment, 1200 fractures (including about 130 hip and 850 vertebral fractures) would be prevented [38•].

In longer-term users, the concerns regarding the rare side effects of AFFs and ONJ are compounded by studies suggesting that longer therapy duration increases these risks. This has led to the widely held opinion that all patients on long-term treatment with bisphosphonates or denosumab should be offered a treatment holiday; however, the existing evidence does not entirely support this. For example, following denosumab discontinuation, rapid bone loss has been described, with around a 5\% incidence of vertebral fractures [39], indicating that treatment holidays on denosumab should not be offered without replacing with another anti-osteoporosis therapy. In terms of long-term bisphosphonate use, reassuringly, a Danish study has demonstrated that users of alendronate, even after 10 years of use, have a lasting reduction in fracture risk compared with matched controls, and that the number of hip fractures prevented is still substantially greater than the number of subtrochanteric femoral fractures occurring [40]. A new systematic review led by the International Osteoporosis Foundation has concluded that drug holidays should only be considered in patients at low fracture risk [41••]. Thus, it is evident that the osteoporosis field needs to vastly improve its approach to communicating the balance of treatment risks and benefits and to work towards countering poorly evidenced stories in the media as and when they occur.

\section{Policies in Healthcare and Osteoporosis Assessment}

Osteoporosis, when compared with other non-communicable diseases, has rarely attracted justifiable levels of attention from governments, policy makers and healthcare providers. National policies on access to and reimbursement of measurement of bone density with dual-energy x-ray absorptiometry (DXA) will have a great impact on the assessment and treatment of this disease. Various regional audits have been published by the International Osteoporosis Foundation (IOF) (https://www.iofbonehealth.org/regional-audits) covering Latin America, the European Union, Eastern Europe the Middle East, Africa, Central Asia and Asia Pacific. These have demonstrated large variations in terms of the epidemiology, financial and societal costs, and burden of osteoporosis e.g. in the Asia Pacific region, whilst Hong Kong, Japan, Republic of Korea, Singapore, Australia and New Zealand had 12-24 DXA machines per million of population, India, Pakistan, China, Indonesia, Philippines, Sri Lanka and Vietnam were severely under-resourced, having less than 1 DXA machine per million of population. The audits demonstrated that insurance or healthcare policies in many countries did not reimburse BMD testing and osteoporosis treatment which served as a barrier to osteoporosis care access. Similar inequalities were seen in Europe, where it was calculated that 11 DXA machines per million of population were needed for adequate osteoporosis care provision. Only 16 European countries fell into this category of "adequate" provision, and 9 countries were considered to have "very inadequate" provision with fewer than 8.4 DXA units per million (the UK, Luxembourg, Czech Republic, Hungary, Bulgaria, Latvia, Lithuania, Poland, Romania and), as shown in Table 1 [42]. In addition, reimbursement for DXA scanning was extremely variable between EU member states, with reimbursement for DXA only offered if the BMD turned out to show osteoporosis in certain countries (Bulgaria and Switzerland), only if BMD was measured after a fracture (Germany), or only if the patient was referred by a specialist (Poland).

Whilst no official IOF audit is available for North America, treatment reimbursement also varies greatly, depending on each patient's health insurance. The evolution of healthcare 
Table 1 Central DXA units per million of the general population available in the EU27 countries. Adapted with permission from [42]

\begin{tabular}{llllll}
\hline Country & DXA units/million & Country & DXA units/million & Country & DXA units/million \\
\hline Austria & 28.7 & GERMANY & 21.1 & NETHERLANDS & 10.7 \\
Belgium & 53.0 & GREECE & 37.5 & POLAND & 4.3 \\
Bulgaria & 1.2 & HUNGARY & 6.0 & PORTUGAL & 26.9 \\
Cyprus & 23.9 & IRELAND & 10.0 & ROMANIA & 2.4 \\
Czech Republic & 5.2 & ITALY & 18.6 & SLOVAKIA & 10.7 \\
Denmark & 14.6 & LATVIA & 4.9 & SLOVENIA & 27.1 \\
Estonia & 8.9 & LITHUANIA & 3.4 & SPAIN & 8.4 \\
Finland & 16.8 & LUXEMBURG & 2.0 & SWEDEN & 10.0 \\
France & 29.1 & MALTA & 9.7 & UK & 8.2 \\
\hline
\end{tabular}

reform in the USA from a "fee for service" system to a system which supports improved disease prevention and care coordination, with financial incentives to encourage healthcare professionals or systems to improve patient outcomes, ought to improve osteoporosis detection and treatment. However, the number of DXA providers has fallen following a major drop in reimbursement in this area, resulting in over 1 million fewer DXA scans performed per year in women aged 50-64 in recent years [43], a change which coincides with a plateau in the secular decline (up until 2012) in age- and sex-adjusted hip fracture rates [44].

\section{What Can We Do to Optimise Osteoporosis Care?}

\section{Secondary Prevention: Treating Those Who Have Already Had a Fracture}

As described by the evidence detailed above, fragility fractures represent a huge burden on societies worldwide. Patient perception of fracture risk is often underestimated as osteoporosis is a silent condition until a fracture happens [45, 46], so primary prevention initiation is usually reliant on health care practitioners who need to have the time and incentive to assess fracture risk and explain the purpose of treatment to their patients. Secondary prevention, in which patients are identified for treatment on the basis of a previous low trauma fracture, is therefore the approach usually taken.

Several methods have been explored to enable fracture risk assessment and initiation of appropriate treatment-some based upon staff, others on IT and others upon a combination of the two. The multi-disciplinary Fracture Liaison Service (FLS) is one of the most successful of these systems [47, 48], incorporating rheumatologists, orthogeriatricians, other physicians, clinical nurse specialists and allied health professionals. Members of the FLS multidisciplinary team, coordinated by a lead clinician, work together to optimise the medical management of patients admitted with fracture, both in hospital and for long-term fracture prevention. [49•]. "Capture the Fracture $® "$, an initiative instituted by the International Osteoporosis Foundation (http://www.capturethefracture. org/), is "a global campaign to facilitate the implementation of coordinated, multi-disciplinary models of care for secondary fracture prevention." Capture the Fracture has provided secondary fracture prevention guidance, and also a global map of secondary fracture prevention services, with a quality grading scheme, graded by assessed application and description of the service $[50,51]$. This scheme has helped to document the huge variation in the quality, scope and availability of secondary prevention facilities, not only within but also between countries. The Capture the Fracture initiative aims to raise the quality and coverage of these services and has been shown to be both clinically valuable and cost-effective [52].

Vertebral fracture case finding is an additive approach to secondary fracture prevention as many such events go undetected - it has been shown that around $12 \%$ of postmenopausal women with osteoporosis have one or more vertebral deformities, but fewer than one in three of these individuals come to clinical attention [53]. Primary care-based screening strategies [54] and history taking methods distinguishing "vertebral fracture-type back pain" from other types of back pain may assist their detection [55]. Different methods for radiological assessment of vertebral fractures exist, including radiographs, CT scans and vertebral fracture software in DXA. The automated detection of prevalent vertebral fracture on CT scans using artificial intelligence technologies will be another avenue for secondary fracture prevention $[56,57]$.

\section{Primary Prevention: Starting Treatment in Individuals at High Fracture Risk}

In osteoporosis, there is an ongoing debate regarding the benefits of a widespread systematic screening approach, leading to higher treatment rates (with its associated cost and side effect risk), and a case finding approach focused on those at highest individual risk (with its associated issue of under- 
Fig. 3 Cumulative incidence of hip fracture in the screening versus control arm in the SCOOP Trial. Produced with permission using data from Shepstone et al., $20198[61 \bullet \bullet]$

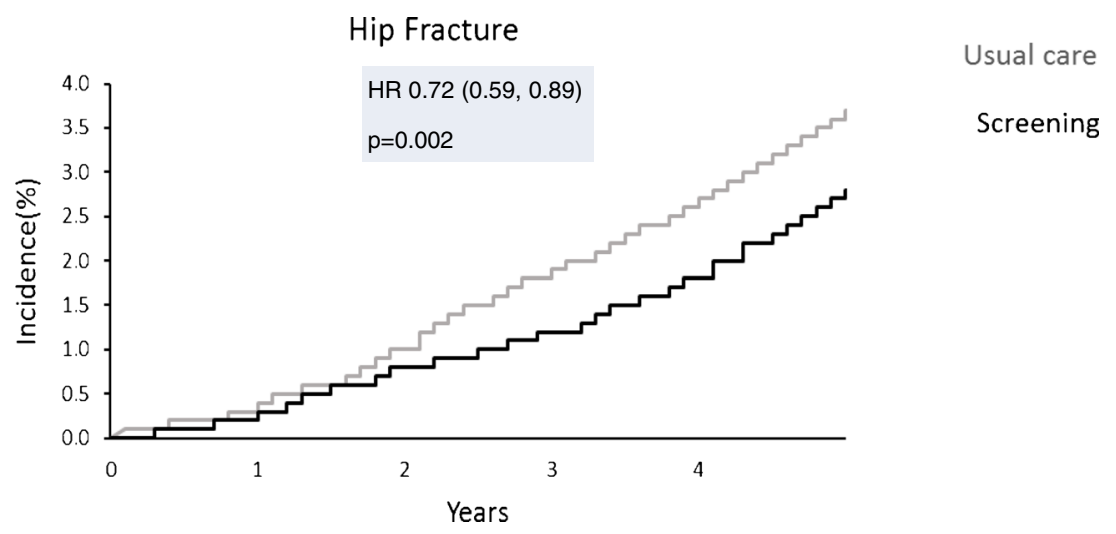

treatment). Whilst DXA-based osteoporosis screening is officially a standard policy in the USA (at age 65 years in women, age 70 in men, and in individuals over 50 years who have suffered a fracture as an adult) [58], in the majority of countries, population screening is not judged to be cost-effective. Primary prevention is therefore generally focused on case finding strategies, reliant on the physician identifying clinical risk factors [15-17, 59].

In the UK, a randomised controlled trial across seven centres was recently undertaken (the UK SCOOP study), examining both the clinical and cost-effectiveness of screening older women in primary care for primary fracture prevention. Around 12,500 older women were randomised to either screening and subsequent treatment (stratified using FRAX hip fracture probability) or usual care. The screening intervention was shown to lead to reduction in hip fracture risk by $28 \%$ (Fig. 3) [60, 61••]. Those at highest baseline fracture risk appeared to benefit most from screening (as would be expected, since these were the individuals targeted for treatment) [62], and importantly, were shown to be cost-effective (the cost per quality adjusted life year (QALY) gained was $£ 2772$ compared with the control arm) [63]. The finding that women who were identified by FRAX as moderate or high risk of fracture benefited most from a screening programme was supported by the Danish risk-stratified osteoporosis strategy evaluation (ROSE) study, though this study found no overall effect on fracture incidence of a screening strategy [64]. A recent evidence report and systematic review for the US Preventive Services Task Force concluded that screening to prevent osteoporosis in women may reduce hip fractures [65].

Once a patient has been identified as requiring fracture risk assessment, the threshold at which treatment should be given will vary according to factors such as healthcare provision, willingness to pay and cost of medications [5]. The majority of guidelines internationally use FRAX as the arbiter of fracture risk, but 38 of the 120 guidelines identified in a recent systematic review gave no direction on translating FRAX probabilities into a treatment decision [23]. Threshold setting is as much a philosophical as scientific process, which decisions around whether a level should be fixed, or age dependent, and calibrated to the specific country. Given the marked variation in fracture rates between countries, this latter consideration seems mandatory, and the benefits and caveats associated with fixed or age-dependent thresholds are presented in detail in [23]. In the UK, FRAX is linked to the agedependent (up to the age of 70 years) thresholds of the National Osteoporosis Guideline Group (NOGG) [17], with the threshold predicated on the probability of future fracture conferred by a prior fracture. This approach has been shown to be cost effective in the UK, and contrasts markedly with that of the UK National Institute of Health and Care Excellence (NICE). In the 2017 technology appraisal of bisphosphonates [66], a pure health economic approach, in the context of a very common disease and extremely inexpensive therapies, led to a $1 \%$ risk of major osteoporotic fracture over 10 years as the threshold above which these medications were considered cost-effective. Unfortunately this was often interpreted as payers as an intervention threshold, a situation which if permitted to continue would have resulted in many adults at low risk of fracture being inappropriately treated [67], but which was later resolved by referral to NOGG guidance for clinical, rather than health economic thresholds [68].

\section{Conclusion}

Recent decades have seen a dramatic transformation in osteoporosis, from having been historically viewed as an inescapable result of ageing, to now being a well-characterised chronic non-communicable disease, with diagnostic criteria, wellestablished methods of risk assessment and an enviable range of therapeutic medications. Despite this backdrop, however, there is evidence from the UK, USA and continental Europe that treatment rates have declined substantially in the last 5 years. With ageing populations and overstretched health services, osteoporosis may often fall off the bottom of the list of priorities for both clinicians and patients. The rare adverse effects of anti-resorptive therapies have become a disproportionately (and inappropriately) major concern, amplified by sensationalised media reports, which have usually been 
inadequately countered by the clinical academic community. These fears and the resulting reduced prescribing have been exacerbated by reductions in reimbursement in the USA, mirrored in new guidance. It is apparent that many patients, doctors and dentists and patients now appear more concerned by the rare but serious side effects of anti-resorptives than they are of the osteoporosis and fragility fractures.

The clear imperative to urgently tackle this issue has been recognised by key organisations such as the International Osteoporosis Foundation and the American Society for Bone and Mineral Research, leading to the publication of recommendations and roadmaps to address the critical care gap in osteoporosis treatment [69••, 70••]. Improved public awareness and public health strategies to improve bone health from a young age will also contribute to prevention of osteoporosis in future generations. Given the rapid ageing of the global population and the importance of good musculoskeletal health in old age, we must come together to ensure that during the coming decade, 2020-2030, hailed by the WHO and others as the "Decade of Healthy Ageing", bone health and fracture prevention become the priority they so urgently need to be.

Acknowledgements We would like to thank the Medical Research Council (UK), National Institute for Health Research, Wellcome Trust, Versus Arthritis, Royal Osteoporosis Society and International Osteoporosis Foundation for supporting this work. This article includes text reproduced/adapted, with permission from [71] and [72].

\section{Compliance with Ethical Standards}

Conflict of Interest EC reports honoraria/travel support from Eli Lilly, $\mathrm{UCB}$ and Amgen outside the submitted work. JL has no disclosures. CH reports no disclosures. CC reports personal fees from ABBH, Amgen, Eli Lilly, GSK, Medtronic, Merck, Novartis, Pfizer, Roche, Servier and Takeda, outside the submitted work. NCH reports personal fees, consultancy, lecture fees and honoraria from Alliance for Better Bone Health, AMGEN, MSD, Eli Lilly, Servier, Shire, Consilient Healthcare and Internis Pharma, outside the submitted work.

Human and Animal Rights and Informed Consent This article does not contain any studies with human or animal subjects performed by any of the authors.

Ethical Approval This review article does not present any previously unpublished original research, and ethical approval is therefore not applicable.

Open Access This article is licensed under a Creative Commons Attribution 4.0 International License, which permits use, sharing, adaptation, distribution and reproduction in any medium or format, as long as you give appropriate credit to the original author(s) and the source, provide a link to the Creative Commons licence, and indicate if changes were made. The images or other third party material in this article are included in the article's Creative Commons licence, unless indicated otherwise in a credit line to the material. If material is not included in the article's Creative Commons licence and your intended use is not permitted by statutory regulation or exceeds the permitted use, you will need to obtain permission directly from the copyright holder. To view a copy of this licence, visit http://creativecommons.org/licenses/by/4.0/.

\section{References}

Papers of particular interest, published recently, have been highlighted as:

- Of importance

•• Of major importance

1. Harvey NC, McCloskey EV, Mitchell PJ, Dawson-Hughes B, Pierroz DD, Reginster JY, et al. Mind the (treatment) gap: a global perspective on current and future strategies for prevention of fragility fractures. Osteoporos Int. 2017;28(5):1507-29.

2. Giangregorio L, Papaioannou A, Cranney A, Zytaruk N, Adachi JD. Fragility fractures and the osteoporosis care gap: an international phenomenon. Semin Arthritis Rheum. 2006;35(5):293-305.

3. Kanis JA, Svedbom A, Harvey N, McCloskey EV. The osteoporosis treatment gap. J Bone Miner Res. 2014;29(9):1926-8.

4. Kanis JA, Johansson H, Oden A, Cooper C, McCloskey EV. Worldwide uptake of FRAX. Arch Osteoporos. 2014;9(1):166.

5. Kanis JA, Oden A, McCloskey EV, Johansson H, Wahl DA, Cooper C. A systematic review of hip fracture incidence and probability of fracture worldwide. Osteoporos Int. 2012;23(9):2239-56.

6. Solomon DH, Johnston SS, Boytsov NN, McMorrow D, Lane JM, Krohn KD. Osteoporosis medication use after hip fracture in U.S. patients between 2002 and 2011. J Bone Miner Res. 2014;29(9): 1929-37.

7. van der Velde RY, Wyers CE, Teesselink E, Geusens PP, van den Bergh JP, de Vries F, et al. Trends in oral anti-osteoporosis drug prescription in the United Kingdom between 1990 and 2012: variation by age, sex, geographic location and ethnicity. Bone. 2016;94: $50-5$.

8. Klop C, Welsing PM, Cooper C, Harvey NC, Elders PJ, Bijlsma JW, et al. Mortality in British hip fracture patients, 2000-2010: a population-based retrospective cohort study. Bone. 2014;66:171-7.

9. Hawley S, Leal J, Delmestri A, Prieto-Alhambra D, Arden NK, Cooper $\mathrm{C}$, et al. Anti-osteoporosis medication prescriptions and incidence of subsequent fracture among primary hip fracture patients in England and Wales: an interrupted time-series analysis. J Bone Miner Res. 2016;31(11):2008-15 A paper demonstrating the importance of national guidance and availability of cheaper generic antiosteoporosis medications on prescribing and subsequent fractures.

10. Shah A, Prieto-Alhambra D, Hawley S, Delmestri A, Lippett J, Cooper C, et al. Geographic variation in secondary fracture prevention after a hip fracture during 1999-2013: a UK study. Osteoporos Int. 2017;28(1):169-78.

11. Greenspan SL, Wyman A, Hooven FH, Adami S, Gehlbach S, Anderson FA Jr, et al. Predictors of treatment with osteoporosis medications after recent fragility fractures in a multinational cohort of postmenopausal women. J Am Geriatr Soc. 2012;60(3):455-61.

12. Svedbom A, Hernlund E, Ivergard M, Compston J, Cooper C, Stenmark J, et al. Osteoporosis in the European Union: a compendium of country-specific reports. Arch Osteoporos. 2013;8(1-2): 137.

13. van der Velde RY, Wyers CE, Teesselink E, Geusens PP, van den Bergh JP, de Vries F, et al. Trends in oral anti-osteoporosis drug prescription in the United Kingdom between 1990 and 2012: variation by age, sex, geographic location and ethnicity. Bone. 2017;94: $50-5$. 
14. Hernlund E, Svedbom A, Ivergard M, Compston J, Cooper C, Stenmark J, et al. Osteoporosis in the European Union: medical management, epidemiology and economic burden : a report prepared in collaboration with the International Osteoporosis Foundation (IOF) and the European Federation of Pharmaceutical Industry Associations (EFPIA). Arch Osteoporos. 2013;8(1-2): 136.

15. Kanis JA, McCloskey EV, Johansson H, Cooper C, Rizzoli R, Reginster JY. European guidance for the diagnosis and management of osteoporosis in postmenopausal women. Osteoporos Int. 2013;24(1):23-57.

16. Lekamwasam S, Adachi JD, Agnusdei D, Bilezikian J, Boonen S, Borgstrom F, et al. A framework for the development of guidelines for the management of glucocorticoid-induced osteoporosis. Osteoporos Int. 2012;23(9):2257-76.

17. Compston J, Cooper A, Cooper C, Gittoes N, Gregson C, Harvey $\mathrm{N}$, et al. UK clinical guideline for the prevention and treatment of osteoporosis. Arch Osteoporos. 2017;12(1):43.

18. Diez-Perez A, Hooven FH, Adachi JD, Adami S, Anderson FA, Boonen S, et al. Regional differences in treatment for osteoporosis. The global longitudinal study of osteoporosis in women (GLOW). Bone. 2011;49(3):493-8.

19. Martin-Merino E, Huerta-Alvarez C, Prieto-Alhambra D, AlvarezGutierrez A, Montero-Corominas D. Secular trends of use of antiosteoporotic treatments in Spain: a population-based cohort study including over 1.5million people and more than 12years of followup. Bone. 2017;105:292-8.

20. Abrahamsen B, Skjodt MK, Vestergaard P. Hip fracture rates and time trends in use of anti-osteoporosis medications in Denmark for the period 2005 to 2015: missed opportunities in fracture prevention. Bone. 2019;120:476-81.

21. Jha S, Wang Z, Laucis N, Bhattacharyya T. Trends in media reports, oral bisphosphonate prescriptions, and hip fractures 1996-2012: an ecological analysis. J Bone Miner Res. 2015;30(12):2179-87.

22. Kanis JA, Hans D, Cooper C, Baim S, Bilezikian JP, Binkley N, et al. Interpretation and use of FRAX in clinical practice. Osteoporos Int. 2011;22(9):2395-411.

23. Kanis JA, Harvey NC, Cooper C, Johansson H, Oden A, McCloskey EV. A systematic review of intervention thresholds based on FRAX: a report prepared for the National Osteoporosis Guideline Group and the International Osteoporosis Foundation. Arch Osteoporos. 2016;11(1):25.

24. Oden A, McCloskey EV, Kanis JA, Harvey NC, Johansson H. Burden of high fracture probability worldwide: secular increases 2010-2040. Osteoporos Int. 2015;26(9):2243-8.

25. Global Burden of Disease Study 2013 Collaborators. Global, regional, and national incidence, prevalence, and years lived with disability for 301 acute and chronic diseases and injuries in 188 countries, 1990-2013: a systematic analysis for the Global Burden of Disease Study 2013. Lancet. 2015;386(9995):743-800.

26. Harvey N, Dennison E, Cooper C. Osteoporosis: impact on health and economics. Nat Rev Rheumatol. 2010;6(2):99-105.

27. Austin PC, Tu JV, Ko DT, Alter DA. Factors associated with the use of evidence-based therapies after discharge among elderly patients with myocardial infarction. CMAJ. 2008;179(9):901-8.

28. Siris ES, Gehlbach S, Adachi JD, Boonen S, Chapurlat RD, Compston JE, et al. Failure to perceive increased risk of fracture in women 55 years and older: the global longitudinal study of osteoporosis in women (GLOW). Osteoporos Int. 2011;22(1):2735 .

29. Järvinen TL, Michaëlsson K, Jokihaara J, Collins GS, Perry TL, Mintzes B, et al. Overdiagnosis of bone fragility in the quest to prevent hip fracture. BMJ. 2015;350:h2088.

30. Järvinen TLN, Michaëlsson K, Aspenberg P, Sievänen H. Osteoporosis: the emperor has no clothes. J Intern Med. 2015;277(6):662-73.
31. Compston J. Overdiagnosis of osteoporosis: fact or fallacy? Osteoporos Int. 2015;26(8):2051-4.

32. Cipriani C, Pepe J, Minisola S, Lewiecki EM. Adverse effects of media reports on the treatment of osteoporosis. J Endocrinol Investig. 2018;41(12):1359-64.

33. Peeters G, Tett SE, Duncan EL, Mishra GD, Dobson AJ. Osteoporosis medication dispensing for older Australian women from 2002 to 2010: influences of publications, guidelines, marketing activities and policy. Pharmacoepidemiol Drug Saf. 2014;23(12):1303-11.

34. Adler RA, El-Hajj Fuleihan G, Bauer DC, Camacho PM, Clarke BL, Clines GA, et al. Managing osteoporosis in patients on longterm bisphosphonate treatment: report of a task force of the American Society for Bone and Mineral Research. J Bone Miner Res. 2016;31(1):16-35.

35. Farmer C, Fenu E, O'Flynn N, Guthrie B. Clinical assessment and management of multimorbidity: summary of NICE guidance. BMJ. 2016;354:i4843

36. Black DM, Rosen CJ. Clinical Practice. Postmenopausal Osteoporosis. N Engl J Med. 2016;374(3):254-62.

37. Gedmintas L, Solomon DH, Kim SC. Bisphosphonates and risk of subtrochanteric, femoral shaft, and atypical femur fracture: a systematic review and meta-analysis. J Bone Miner Res. 2013;28(8): 1729-37.

38. Black DM, Abrahamsen B, Bouxsein ML, Einhorn T, Napoli N. Atypical femur fractures: review of epidemiology, relationship to bisphosphonates, prevention, and clinical management. Endocr Rev. 2019;40(2):333-68 A key, up to date review on atypical femoral fractures, how to prevent and manage them.

39. Brown JP, Roux C, Törring O, Ho P-R, Beck Jensen J-E, Gilchrist $\mathrm{N}$, et al. Discontinuation of denosumab and associated fracture incidence: analysis from the fracture reduction evaluation of denosumab in osteoporosis every 6 months (FREEDOM) trial. J Bone Miner Res. 2013;28(4):746-52.

40. Abrahamsen B, Eiken P, Prieto-Alhambra D, Eastell R. Risk of hip, subtrochanteric, and femoral shaft fractures among mid and long term users of alendronate: nationwide cohort and nested casecontrol study. Bmj. 2016;353:i3365.

41.• Dennison EM, Cooper C, Kanis JA, Bruyere O, Silverman S, McCloskey E, et al. Fracture risk following intermission of osteoporosis therapy. Osteoporos Int. 2019;30(9):1733-43. A new systematic review on intermission of osteoporosis therapy, known as "treatment holidays", led by the International Osteoporosis Foundation.

42. Kanis JA, Borgstrom F, Compston J, Dreinhofer K, Nolte E, Jonsson L, et al. SCOPE: a scorecard for osteoporosis in Europe. Arch Osteoporos. 2013;8:144.

43. Overman RA, Farley JF, Curtis JR, Zhang J, Gourlay ML, Deal CL. DXA utilization between 2006 and 2012 in commercially insured younger postmenopausal women. J Clin Densitom. 2015;18(2): $145-9$.

44. Lewiecki EM, Adler RA, Curtis J, Gagel RF, Saag KG, Singer A, et al. Hip fractures and declining DXA testing: at a breaking point? J Bone Miner Res. 2016. American Society for Bone and Mineral Research Annual Scientific Meeting (Abstract 1077).

45. Grover ML, Edwards FD, Chang YH, Cook CB, Behrens MC, Dueck AC. Fracture risk perception study: patient self-perceptions of bone health often disagree with calculated fracture risk. Womens Health Issues. 2014;24(1):e69-75.

46. Gregson CL, Dennison EM, Compston JE, Adami S, Adachi JD, Anderson FA Jr, et al. Disease-specific perception of fracture risk and incident fracture rates: GLOW cohort study. Osteoporos Int. 2014;25(1):85-95.

47. Eisman JA, Bogoch ER, Dell R, Harrington JT, McKinney RE Jr, McLellan A, et al. Making the first fracture the last fracture: 
ASBMR task force report on secondary fracture prevention. J Bone Miner Res. 2012;27(10):2039-46.

48. Mitchell PJ. Best practices in secondary fracture prevention: fracture liaison services. Curr Osteoporos Rep. 2013;11(1):52-60.

49. Drew S, Judge A, Cooper C, Javaid MK, Farmer A, GoobermanHill R. Secondary prevention of fractures after hip fracture: a qualitative study of effective service delivery. Osteoporos Int. 2016;27(5):1719-27 A paper discussing ways of developing best models of secondary fracture prevention after hip fracture, through structured interviewing of health professionals.

50. Akesson K, Marsh D, Mitchell PJ, McLellan AR, Stenmark J, Pierroz DD, et al. Capture the fracture: a best practice framework and global campaign to break the fragility fracture cycle. Osteoporos Int. 2013;24(8):2135-52.

51. Javaid MK, Kyer C, Mitchell PJ, Chana J, Moss C, Edwards MH, et al. Effective secondary fracture prevention: implementation of a global benchmarking of clinical quality using the IOF capture the fracture(R) best practice framework tool. Osteoporos Int. 2015;26(11):2573-8.

52. Mitchell P, Akesson K, Chandran M, Cooper C, Ganda K, Schneider M. Implementation of models of care for secondary osteoporotic fracture prevention and orthogeriatric models of care for osteoporotic hip fracture. Best Pract Res Clin Rheumatol. 2016;30(3):536-58.

53. Cooper C, Atkinson EJ, O'Fallon WM, Melton LJ. Incidence of clinically diagnosed vertebral fractures: a population-based study in Rochester, Minnesota, 1985-1989. J Bone Miner Res. 1992;7(2): 221-7.

54. Clark EM, Gould V, Morrison L, Ades AE, Dieppe P, Tobias JH. Randomized controlled trial of a primary care-based screening program to identify older women with prevalent osteoporotic vertebral fractures: cohort for skeletal health in Bristol and Avon (COSHIBA). J Bone Miner Res. 2012;27(3):664-71.

55. Clark EM, Gooberman-Hill R, Peters TJ. Using self-reports of pain and other variables to distinguish between older women with back pain due to vertebral fractures and those with back pain due to degenerative changes. Osteoporos Int. 2016;27(4):1459-67.

56. Oei L, Koromani F, Breda SJ, Schousboe JT, Clark EM, van Meurs $\mathrm{JB}$, et al. Osteoporotic vertebral fracture prevalence varies widely between qualitative and quantitative radiological assessment methods: the Rotterdam study. J Bone Miner Res. 2018;33(4): 560-8.

57. Muehlematter UJ, Mannil M, Becker AS, Vokinger KN, Finkenstaedt T, Osterhoff $\mathrm{G}$, et al. Vertebral body insufficiency fractures: detection of vertebrae at risk on standard CT images using texture analysis and machine learning. Eur Radiol. 2019;29(5):2207-17.

58. Cosman F, de Beur SJ, LeBoff MS, Lewiecki EM, Tanner B, Randall S, et al. Clinician's guide to prevention and treatment of osteoporosis. Osteoporos Int. 2014;25(10):2359-81.

59. Lekamwasam S, Adachi JD, Agnusdei D, Bilezikian J, Boonen S, Borgstrom F, et al. An appendix to the 2012 IOF-ECTS guidelines for the management of glucocorticoid-induced osteoporosis. Arch Osteoporos. 2012;7(1-2):25-30.

60. Shepstone L, Fordham R, Lenaghan E, Harvey I, Cooper C, Gittoes $\mathrm{N}$, et al. A pragmatic randomised controlled trial of the effectiveness and cost-effectiveness of screening older women for the prevention of fractures: rationale, design and methods for the SCOOP study. Osteoporos Int. 2012;23(10):2507-15.
61.• Shepstone L, Lenaghan E, Cooper C, Clarke S, Fong-Soe-Khioe R, Fordham R, et al. Screening in the community to reduce fractures in older women (SCOOP): a randomised controlled trial. Lancet. 2018;391(10122):741-7 A randomised controlled trial of community screening for fracture risk in UK women demonstrating a reduction in hip fractures in screened women.

62. McCloskey E, Johansson H, Harvey NC, Shepstone L, Lenaghan E, Fordham R, et al. Management of patients with high baseline hip fracture risk by FRAX reduces hip fractures-a post hoc analysis of the SCOOP study. J Bone Miner Res. 2018;33(6):1020-6.

63. Turner DA, Khioe RFS, Shepstone L, Lenaghan E, Cooper C, Gittoes N, et al. The cost-effectiveness of screening in the community to reduce osteoporotic fractures in older women in the UK: economic evaluation of the SCOOP study. J Bone Miner Res. 2018;33(5):845-51.

64. Rubin KH, Rothmann MJ, Holmberg T, Hoiberg M, Moller S, Barkmann R, et al. Effectiveness of a two-step population-based osteoporosis screening program using FRAX: the randomized riskstratified osteoporosis strategy evaluation (ROSE) study. Osteoporos Int. 2018;29(3):567-78.

65. Viswanathan M, Reddy S, Berkman N, Cullen K, Middleton JC, Nicholson WK, et al. Screening to prevent osteoporotic fractures: updated evidence report and systematic review for the US preventive services task force USPSTF evidence report: screening to prevent osteoporotic FracturesUSPSTF evidence report: screening to prevent osteoporotic fractures. JAMA. 2018;319(24):2532-51.

66. NICE. TA464: bisphosphonates for treating osteoporosis. London: National Institute for Health and Care Excellence; 2017.

67. Harvey NC, McCloskey E, Kanis J, Compston J, Cooper C. Bisphosphonates in osteoporosis: NICE and easy? Lancet. 2017;390(10109):2243-4.

68. Harvey NC, McCloskey E, Kanis JA, Compston J, Cooper C. Costeffective but clinically inappropriate: new NICE intervention thresholds in osteoporosis (technology appraisal 464). Osteoporos Int. 2018;29(7):1511-3.

$69 . \bullet$ Khosla S, Hofbauer LC. Osteoporosis treatment: recent developments and ongoing challenges. Lancet Diabetes Endocrinol. 2017;5(11):898-907 An important review article addressing the problem of osteoporosis treatment acceptance amongst patients and strategies to address this.

70.• Harvey NC, McCloskey E. Gaps and solutions in bone health: a global framework for improvement. 2016. https://www. iofbonehealth.org/thematicreport-2016. A report produced by the International Osteoporosis Foundation to describe 10 key care gaps which are hindering osteoporosis treatment and fracture prevention worldwide.

71. Harvey NCW, McCloskey EV, Rizzoli R, Kanis JA, Cooper C, Reginster J-Y. Osteoporosis: treatment gaps and health economics. In: Huhtaniemi I, Martini L, editors. Encyclopedia of endocrine diseases. Second ed. Oxford: Academic Press; 2019. p. 288-95.

72. Liu J, Curtis EM, Cooper C, Harvey NC. State of the art in osteoporosis risk assessment and treatment. J Endocrinol Investig. 2019;42(10):1149-64.

Publisher's Note Springer Nature remains neutral with regard to jurisdictional claims in published maps and institutional affiliations. 